\title{
O avesso do bordado: Walter Benjamin, José Leonilson e Lu Menezes
}

\author{
Francisco Camêlo ${ }^{1}$
}

\begin{abstract}
RESUMO: Este artigo reflete sobre o gesto de bordar no trabalho do artista plástico José Leonilson e da poeta Lu Menezes, a partir do pensamento de Walter Benjamin sobre a infância e, em particular, sobre a imagem da "Caixa de costura" (Der Nähkasten), de Infância em Berlim por volta de 1900, que guarda ferramentas dadas às crianças como atividade iniciatória a escrita.
\end{abstract}

Palavras-chave: escrita; bordado; poesia; artes visuais; linguagem artística infantil.

Em um fragmento de Infância em Berlim por volta de 1900 (Berliner Kindheit um 1900), Walter Benjamin rememora um de seus lugares preferidos quando criança: $A$ escrivaninha (Das Pult). No móvel, engenhosamente construído, em que o assento podia ser regulado de modo que ficasse mais ou menos próximo de onde se escrevia, o menino burguês alemão guardava sua coleção de selos e cartões-postais, e praticava uma de suas atividades prediletas: a decalcomania. $\mathrm{O}$ pequeno Walter recortava figuras de "crianças sentadas nos galhos das árvores", do "tigre que se dobra ao caçador, cuja espingarda acaba de detonar" e do "farol com o veleiro em frente"; todas as imagens eram um "mundo descolorido", coberto por um "sopro de névoa", do qual, pouco a pouco, "a cor despontava doce e íntegra" sob a ponta dos dedos da criança, que raspava o papel (BENJAMIN, 2012).

O passatempo infantil servia de pretexto para o menino adiar os deveres escolares e revisitar velhos cadernos que possuíam um valor especial porque tinham sido retirados do poder do professor. Ao contrário da carteira escolar, a escrivaninha era cúmplice do pequeno Benjamin: "Assim, aquela escrivaninha guardava, sem dúvida, certa semelhança ao banco escolar, mas sua vantagem era que nela eu ficava protegido e dispunha de espaço para esconder coisas de que ele não deveria saber (BENJAMIN, 2012, p. 121)”. Neste pequeno reino, as reivindicações dos elementos de tortura (compassos, dicionários etc.) não tinham voz e a criança, revigorada pelo móvel, podia perder tempo contemplando cadernos e lendo livros.

A propósito de "A escrivaninha", a crítica argentina Beatriz Sarlo, no ensaio "Verdade dos detalhes", comenta:

\footnotetext{
Nas lembranças sobre a ordem da escrivaninha e a prática da coleção, somada à lembrança do prazer das decalcomanias, bem podemos encontrar, nesse Benjamin criança, as formas do outro Benjamin, do investigador que persegue os signos da modernidade através das passagens de Paris, das vitrines e dos colecionadores. Para seu livro sobre as passagens de Paris, Benjamin, reúne, à maneira de um colecionador, centenas de citações, de fotografias, de plantas. Estabelece e reforma obsessivamente as partes que mais tarde seriam capítulos; copia textos escritos por outros, passando-os para seus cadernos como se eles fossem decalcomanias que, nesse trânsito do livro ao caderno, produzissem novas imagens (SARLO, 2013, p. 45).
}

No gesto do colecionador de citações sobrevive o impulso do Benjamin criança, que, durante as viagens de verão, caçava borboletas no jardim do Brauhausberg e as guardava na "caixa espaçosa na parede do meu quarto (BENJAMIN, 2012, p. 81)". As "ardorosas caçadas" atraíam frequentemente o menino para lugares ermos, onde ele se defrontava com "a conjuração do vento e dos perfumes, das folhagens e do sol, que,

IPOTESI, JUIZ DE FORA, v.22, n.2, p.118-127, jul./dez. 2018 
possivelmente, comandavam o voo das borboletas (Idem)". O pequeno caçador, encantado com o movimento das borboletas, desejava "dissolver-me em luz e em ar a fim de me aproximar da presa sem ser notado e poder dominá-la (Idem)". O agitar e o oscilar de asas das borboletas encantam o caçador, levando-lhe ao desejo de se assemelhar à presa para capturá-la:

[...] quanto mais me achegava com todas as fibras ao inseto, quando mais assumia intimamente a essência da borboleta, tanto mais ela dotava em toda ação o matiz da decisão humana, e, por fim, era como se sua captura fosse o único preço pelo qual minha condição de ser humano pudesse ser reavida (Idem).

Conhecer a "essência da borboleta" significa, para o menino, o risco da perda de sua forma humana, à medida que for se confundindo com o inseto, através de um jogo fisionômico do corpo. Assim como a criança escondida atrás das cortinas ou da mesa da casa berlinense, a experiência da criança caçadora e colecionadora de borboletas acontece em uma dinâmica temporal intermitente em que as formas vão e deixam de ser e onde a ameaça de confusão mimética é iminente (BINES, 2017). A capacidade infantil de se tornar semelhante às coisas, adotando seus comportamentos e formas através da brincadeira, é reconhecida por Benjamin, no ensaio de 1933, "A doutrina das semelhanças" (Lehre vom Ähnlichen), como um processo engendrado pela faculdade mimética: "A criança não brinca apenas de ser comerciante ou professor, mas também moinho de venho e trem. (BENJAMIN, 2012b, p. 117)". Se, por um lado, a criança é capaz assemelhar-se com as coisas, por outro, esta figura alegórica é igualmente capaz de acessar, por meio de associações imprevistas entre as palavras, o arquivo de semelhanças não sensíveis da linguagem:

\footnotetext{
Nessa perspectiva, a linguagem seria a mais alta aplicação da faculdade mimética: um medium em que as faculdades primitivas de percepção do semelhante penetram tão completamente, que ela se converteu no medium em que as coisas se encontram e se relacionam, não diretamente, como antes, no espírito do vidente ou do sacerdote, mas em suas essências, nas substâncias mais fugazes e delicadas, nos próprios aromas (Idem, p. 121-122).
}

Do cenário de violência, desordem e tensão, onde o menino caçador arduamente captura a borboleta, para, em seguida, colocá-la na caixa afixada à parede do quarto, sobrevive, no adulto que relê a própria infância, a palavra "Braushausberg". Esvaziada de sua primeira acepção (o jardim da casa de veraneio), ela conserva "o insondável com que os nomes da infância fazem frente aos adultos" e também condensa o idioma secreto por meio do qual as borboletas e as flores se comunicavam. "Assim, naquele ar preenchido pelas borboletas, vibra a palavra 'Brauhausberg' (BENJAMIN, 2012, p. 82)."

\section{A caixa de costura}

Em outro fragmento bastante conhecido de seu livro autobiográfico, "A caixa de costura" (Der Nähkasten), Benjamin relaciona o gesto de costurar ao de desenhar, a partir de sua experiência infantil. O pequeno Walter, quando criança, gostava de observar a mãe sentada à janela com os materiais da caixa de costura. Mas ao contrário da Bela Adormecida, que pica por acidente o dedo em uma agulha e cai num sono por anos, ela (a mãe), quando costurava, protegia-se com um dedal, uma espécie de "pequena coroa" que a transformava, para os filhos, em uma rainha. 
Pois gostávamos de nos apoderar daquela pequena coroa que, às escondidas, podia nos cingir. [...] Não poderiam ter achado outro tratamento em que, a meu ver, se manifestasse de modo mais evidente a autoridade de minha mãe. Como todos os genuínos tronos de soberano; também o seu tinha sua jurisdição, que era a mesa de costura. E ocasionalmente me foi dado percebê-la (BENJAMIN, 2012, p. 129).

A mãe exercia seu poder de rainha fazendo arremates nas roupas do filho antes de ele fazer uma visita ou compras, o que acabava irritando-o. Por sua vez, o menino, ao ser submetido às ferramentas da caixa, questionava se a tesoura e a agulha se destinariam de fato à costura. A dúvida quanto a utilidade das coisas é reforçada principalmente pelos carreteis de linha. Tal como o dedal materno, os carreteis também estimulavam o desejo do menino de tocar a cavidade dos objetos: "Tão grande era a tentação de fincar a ponta dos dedos no centro da etiqueta, tão íntima a satisfação quando se rompia e eu tateava o furo debaixo (Idem, p. 130)". Aqui, pelos olhos e pelo tato da criança, Benjamin alude à descoberta infantil do corpo e do sexo femininos, como observa Jeanne Marie Gagnebin (2013). Neste sentido, trata-se uma infância que descobre a sexualidade e se interessa por uma "dimensão subterrânea e misteriosa (GAGNEBIN, 2013, p. 92)". Além da cavidade do carretel, tal dimensão subterrânea está presente também na região inferior da caixa de costura, onde "havia o fundo escuro, a desordem, onde reinava o entrançado desfeito, e onde sobras de elástico, ganchos, colchetes, retalhos de seda se amontoavam (BENJAMIN, 2012 , p. 130)". Se, na parte superior da caixa, as agulhas, as tesouras e os carreteis de linha estão ordenados, na parte inferior esconde-se uma confusão de retalhos e sobras de materiais com os quais a criança vai não apenas construir seu mundo, mas também se reconciliar com a costura. Segundo Gagnebin,

O menino só se reconcilia com o gesto feminino da costura ao apropriar-se dele neste jogo de bordados no papel, dado às crianças como exercício preliminar à escrita. [...] Mas a criança não borda somente para ver aparecer as flores esboçadas no lado 'certo' do papel; ela se encanta também pelo verso, por esse avesso labiríntico inseparável da ordem do desenho (GAGNEBIN, 2013, p. 92).

Neste sentido, o que encanta o pequeno Benjamin é menos o lado direto do bordado, onde está a costura bem alinhavada, e mais os fios emaranhados do avesso, que dão ao desenho o aspecto de esboço:

Quando mais cedo escurecia, tanto mais frequentemente pedíamos as tesouras. Então ficávamos, nós também, horas seguindo com o olhar a agulha, da qual pendia indolente um grosso fio de lã. Pois sem dizê-lo, cada um de nós tomara de suas coisas que pudessem ser forradas - pratos de papel, limpa-penas, capas - e nelas alinhavávamos flores segundo o desenho. E à medida que o papel abria caminho à agulha com um leve estalo, eu cedia à tentação de me apaixonar pelo reticulado do avesso que ia ficando cada vez mais confuso a cada ponto dado, com o qual, na frente, me aproximava da meta (BENJAMIN, 2012, p. 131).

Como seria a caixa de costura que tanto fascinara Walter Benjamin? É difícil imaginar, hoje, sua cor, seu tamanho. No entanto, pode-se conhecer os objetos que artistas e poetas guardam em suas caixinhas de costura e com os quais bordam, desenham e traçam suas escritas expandidas. Quando lidam com tesouras, agulhas e linhas, são contagiados por um gesto infantil, próximo ao do menino Benjamin diante da caixa de costura.

\section{O fio borda o fim}

Quando descobriu-se portador do vírus da Aids, o artista plástico José Leonilson começou a explorar a expressividade de novos materiais e técnicas, como a costura e o bordado. Linha, tesoura e agulha tornaram-se as ferramentas de trabalho do artista cearense no momento em que a tinta acrílica começou a fragilizar sua saúde. No final da década de IPOTESI, JUIZ DE FORA, v.22, n.2, p.118-127, jul./dez. 2018 
1980, os trabalhos de Leonilson passam a registrar sua convivência com a doença, o que acaba por dar à sua obra uma expressão mais delicada, intimista e confessional, à maneira de um diário afetivo. É o próprio Leonilson, aliás, quem, numa entrevista a Adriano Pedrosa, identifica sua obra com o gênero do diário:

\footnotetext{
Adriano Pedrosa: Você acha que seu trabalho é um diário? Leonilson: É, os trabalhos são completamente diários.

Adriano Pedrosa: E então são completamente pessoais?

Leonilson: São completamente pessoais. Mas mesmo assim, quando uma pessoa olha para isso, você não acha que a pessoa estabelece uma relação com as coisas dela? Porque isso acontece na vida de todo mundo, né? A gente está sempre tendo desilusões amorosas. Eu fico falando sobre isso. Eu sou o... Como é que a gente diz? Eu fico falando sobre mim, sobre as minhas relações. É o diário (PEDROSA, 2014, p. 235).
}

Além de trabalhos de costura, o diário de Leonilson é composto por desenhos e fitas cassete gravadas entre 1990 e 1993, nos últimos anos de sua vida. Tanto nos diários visuais, quanto nos sonoros, ele faz uma narração de si a partir da perspectiva da doença que o vitimaria. Nestes registros pode-se ver um gesto que faz da fragilidade do corpo a força criadora de sua arte: embora esteja afetado pela doença, o artista precisa se expressar e encontra no suporte do diário o meio para fazê-lo, ainda que de modo elusivo e/ou velado. Para a pesquisadora Ana Chiara (2009), a "escrita bordada" de Leonilson possui um aspecto performatizado que endereça uma "estratégia de sedução". Essa intimidade, porém, não deseja confessar coisa alguma, mas antes questionar a expectativa do outro e o fazer artístico institucionalizado.

Fig. 1, O PERIGOSO, 1992, sangue e tinta de caneta permanente

Em 1992, Leonilson traça de forma poética uma imagem do seu corpo doente numa série de sete desenhos, dos quais se destaca $O$ perigoso, um desenho feito com uma gota de sangue contaminado. Outra imagem de si, na qual sua condição é retratada, é a obra $E l$ puerto (1992), um pequeno espelho coberto por um tecido, onde estão bordados em linha 
azul o nome LEO e números que indicam a idade, a altura e o peso do sujeito - 35, 60, 1,79. Os dois trabalhos corroboram o modo performático e esquivo de Leonilson se dirigir ao outro.

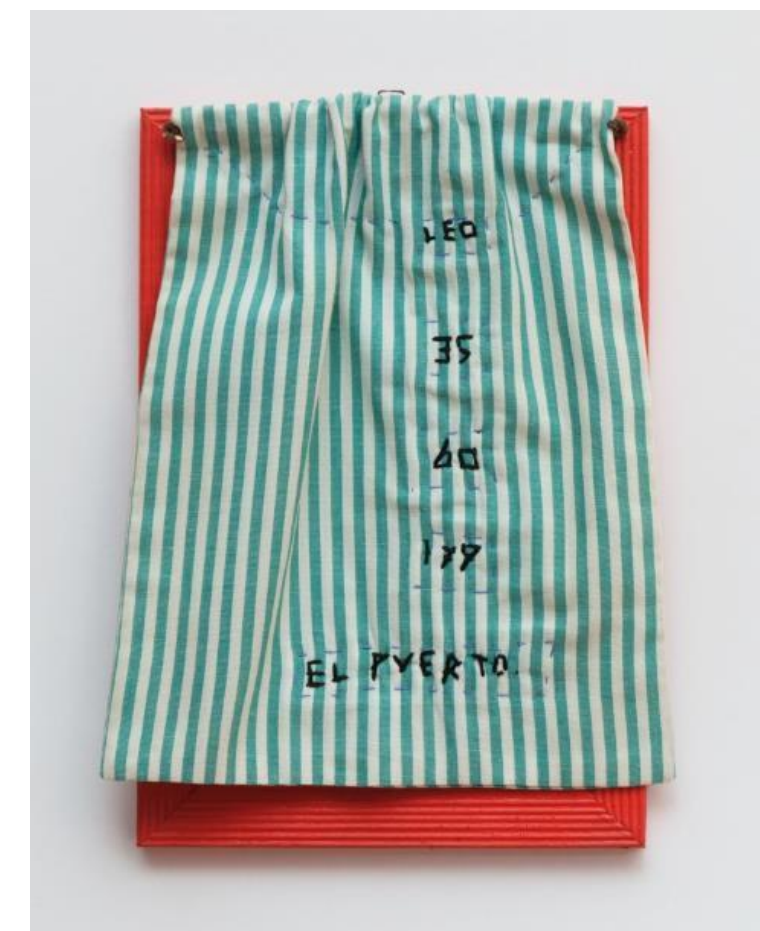

Fig. 2, EL PUERTO, 1992, linha sobre tecido de algodão e espelho emoldurado

Ao fazer do corpo doente um polo de irradiação de forças ativas e criadoras, Leonilson se aproxima do conceito de trágico de Friedrich Nietzsche, que afirma a dor e a alegria como indispensáveis à vida. No autobiográfico Ecce Homo, o filósofo se apresenta de maneira paradoxal, atribuindo sua existência à combinação da fragilidade do pai com a energia da mãe. Em Nietzsche, a experiência da doença é vontade de saúde: é da ótica do doente que respira o ar rarefeito das montanhas que o filósofo escreve seus livros:

(...) para alguém tipicamente são, ao contrário, o estar enfermo pode ser até um enérgico estimulante ao viver, ao mais-viver. De fato, assim me parece agora aquele longo tempo de doença: descobrir a vida e a mim mesmo como que devo, saboreei todas as boas e mesmo pequenas coisas, como outros não as teriam sabido saborear - fiz da minha vontade de saúde, de vida, a minha filosofia... Pois atente-se para isto: foi durante os anos de minha menor vitalidade que deixei de ser um pessimista (NIETZSCHE, 1986, p. 47-48).

Transformar a menor vitalidade em uma nova saúde, em uma saúde ativa e desviante da saúde dominante, como faz Nietzsche e como quer Gilles Deleuze em "A literatura e vida". É este o modo como Leonilson encena pela arte a experiência da doença. Dito de outra maneira: com sua vontade de saúde e sensibilidade aguçada, o artista se contagia de múltiplos impulsos vitais do entorno e expressa um pensamento artístico que interpreta a dor como indispensável à vida. Como diz Benjamin nos "Pequenos trechos sobre arte", "existe um alimento cru da experiência - exatamente como existe um alimento cru do estômago -, ou seja: experiências no próprio corpo (BENJAMIN, 2012, p. 282283)". Com linha, tesoura e agulha, as ferramentas de sua caixa de costura, Leonilson diz sim à dor não para assumir uma vitimização, mas para afirmar a totalidade da existência, IPOTESI, JUIZ DE FORA, v.22, n.2, p.118-127, jul./dez. 2018 
incluindo, aí, o alegre e o doloroso, a vida e a morte. Trata-se de uma superação do estar doente por meio de uma liberdade artística alegre e trágica.

Se, em "A caixa de costura" de Walter Benjamin, a experiência têxtil revela o fascínio do menino tanto pelo avesso da costura quanto pelos retalhos de tecido escondidos no fundo da caixa, os quais ele vai rearticular, transformando-os num mundo de formas; no caso de Leonilson, a costura, aprendida com a mãe, serve, no momento em que seu corpo está fragilizado pela doença, como suplemento da arte, resgatando certa inventividade infantil avessa aos modelos e padrões de perfectibilidade. Assim, a costura acrescenta ao trabalho de Leonilson um gesto infantil que o diferencia das fases anteriores, na medida em que acentua na sua arte a dimensão do inacabado, presente em seus bordados e desenhos, que reagem contra a ideia de arte perfeita. Escapando aos critérios e aos modos de fazer estéticos institucionalizados, o artista borda seu fim em tecidos que revitalizam e dão visibilidade ao exercício feminino e infantil da costura.

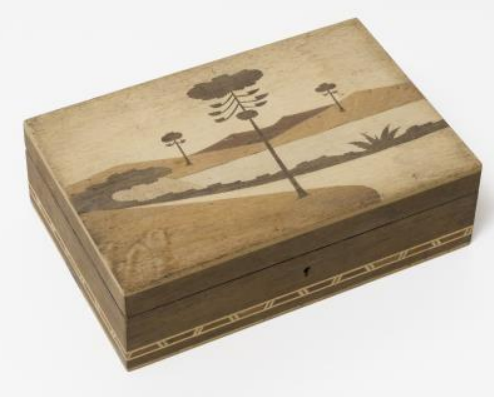

Fig. 3, Caixa de costura de Leonilson



Fig. 4, Caixa de costura de Leonilson

\section{O bordado da escrita poética}

Convidada, em 2015, por Augusto Massi, para escrever em dupla um livro de poesia para a editora Luna Parque, a poeta Lu Menezes reage, no feminino, à proposta do amigo de "revirar nossas caixas de ferramentas e tentar construir um livro prático e 
funcional ${ }^{2}$ ". Avessa ao universo de uma caixa de ferramentas, isto é, às temáticas dos poemas fabricados pelo parceiro de livro, Lu Menezes propõe uma "contrapartida feminina", afinal tais entidades (pregos, parafusos, tachinhas etc.) são, para ela, um mistério. "Admiradora dos infindáveis fins e fios a que se destinaram e destinam agulhas e congêneres", ela empenha-se, na oficina poética, a bordar sua escrita feminina com as ferramentas da caixa de costura:

\footnotetext{
O Massi sugeriu falarmos sobre "uma caixa de ferramentas" - parafusos, pregos etc., e gostei da ideia. Mas, mesmo sem bordar, ocorreu-me o "bordado" e a "caixa de costura" que ele supõe, resgatando um título engavetado, Onde no mundo, e usando como que "em sua tinta", diretamente vinculado a um "risco" comprado há muitos anos numa loja parisiense ${ }^{4}$.
}

Foi assim que o livro arquitetado em conjunto pelos dois poetas recebeu o título Gabinete de curiosidades: uma "pequena fábrica" onde coabitam pregos, alfinetes, parafusos, linhas, tesoura e agulhas. Trata-se de uma "micro poética" ou de um "minimalismo satírico", para retomar as expressões dos autores do livro. Aqui, interessa, especialmente, comentar alguns poemas da "micro poética" de Onde no mundo, a primeira parte de Gabinete de curiosidades, onde estão reunidos os poemas escritos por Lu Menezes. O poema "Onde no mundo", que serve como título, foi escrito a partir de um dado biográfico, como conta a poeta em entrevista concedida à Masé Lemos:

Terá também contribuído para minha decisão [de aceitar o convite de Augusto Massi] deparar-me há vários anos, nas galerias Lafayette, em Paris, com uma lojinha chamada Le bonheur des dames, onde uma espécie de "risco" em preto e branco na vitrine me atraiu: nele, uma mulher mostrava para uma menina um ponto qualquer do globo terrestre, apontando-o com uma varinha. A legenda da cena era Onde no mundo. Comprado e guardado o "esquema", cheguei a pensar nesta legenda como título de livro de poesia ${ }^{5}$.

Instigada pela caixa de ferramentas de Massi, a poeta escreve sobre "o bordado e a caixa de costura que ele supõe" a partir de uma experiência pessoal: a compra de um "risco" em preto em branco, "denominado Où dans le monde", no qual "uma menina assistia a professora / com sua varinha apontar / em lugar qualquer / em nosso globo / um mero ponto / do mundo / um lá / ali / acolá (p. 26)".

Se é verdade que o bordado é um "ponto estético de vista", como afirma em"Linhas de tensão", também é verdade que "a gente, obviamente, quase nunca vê / tudo o que uma coisa é (Idem)". Por isso, "um lugar qualquer do globo terrestre" pode coincidir "com um ponto de bordado", de modo que "O lá se converteria em cá, o ali em aqui / no bastidor de alguma mulher / que a cada ponto a cada instante / seu e de tudo - aprenderia / o quê? além do preciso / presente impreciso / dela no mundo? (p. 27)".

Essa poesia, que extrai delicadamente do cotidiano e do banal (uma imagem à venda em uma loja, por exemplo) o material de sua reflexão criativa, é feita de uma fecundidade de questões não respondidas, como pode-se ler no final de "Onde no mundo" ou em "Linhas de navegação", onde aflora a questão do gênero (gender). Nesse poema, Lu Menezes se interroga sobre "a não-participação masculina na produção manual da renda em comunidades", uma vez que "Os marinheiros, eles bordavam" (p. 13) e "os meninos também bordavam, / e todas as crianças usufruíam as várias cores de fios em suas amostras (p. 25)". Mas, ainda que o pensamento poético prefira "imaginar um marinheiro / bordando nas horas vagas seu navio (p. 13)", ele não deixa de interrogar a si mesmo: "Preso ao 
bordado preso ao navio, / terá a sua agulha ponto a ponto / remoído alguma doída saudade? (p. 14)". Questionada se sua reação à proposta de Augusto Massi corresponderia, em termos gráficos e temáticos, a uma divisão entre masculino e feminino, fabril e têxtil, Lu Menezes responde:

\begin{abstract}
Minha reação "feminina" à ideia "masculina" do Massi foi apenas instintiva, desprovida de qualquer ironia (aliás, acredito em diferenças extraculturais entre os dois sexos). Não teve importância ser "masculina": afinal, eu dispunha de liberdade, e a margem de manobra envolvida - tanto no título libertário como na "caixa" proposta - era para mim tão ampla que a sensação foi não de limitação, mas expansão. Nossas perspectivas, claro, diferenciaram-se ${ }^{7}$.
\end{abstract}

Ainda sobre essa questão, Augusto Massi observa que sua dicção poética e a de Lu Menezes possuem mais semelhanças do que diferenças. Elas são uma "conversa têxtil", a partir da percepção daquilo que existe de mais diminuto, miúdo, microscópico. Massi ressalta, ainda, que os poemas de Onde no mundo possuem como marca uma "curiosidade infernal" que "navega segundo a bússola da imaginação" A função lúdica do pensamento que Augusto Massi reconhece na poesia de Lu Menezes é, possivelmente, aquilo que impulsiona a poeta a brincar com as palavras ("a renda como fonte de renda (p.11)"), aproximando a "poesia, essa impalpável (p. 12)" do bordado, uma "ideia-ônibus que transposta / de corpos celestes a suturas nos terrestres (p. 17)". E ainda a leva a se interessar tanto pelo lado direto quanto pelo avesso do bordado:

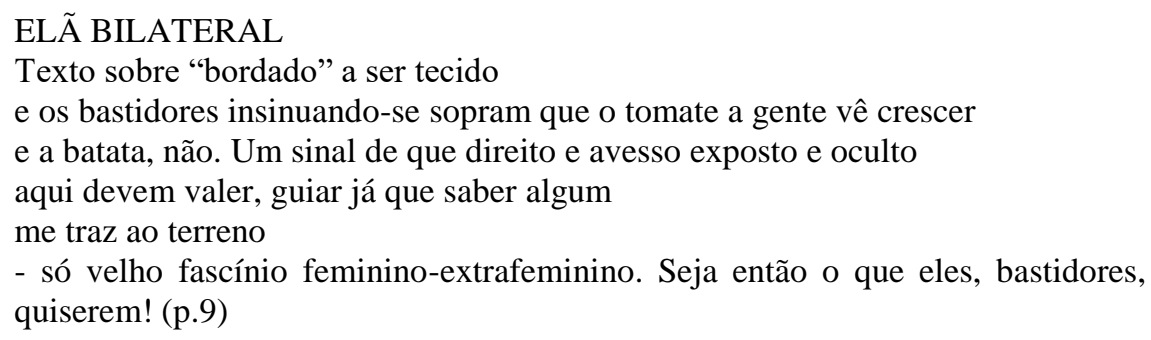

Sobre este poema, que abre Onde no mundo, Lu Menezes diz: ele expressa a "ininterrupta dualidade que, de múltiplas maneiras, permeia nossa existência". E recordase de que "tudo o que bordei reduziu-se, na infância, a (já nem me lembro) uma flor ou um sol no quadrado de pano ${ }^{10 "}$. Para a poeta, o desenho é o denominador comum entre escrita e bordado; no entanto, o tempo deste último convida a uma certa introspecção, ao passo que o tempo do desenho é veloz. Neste sentido, pode-se perguntar também sobre o ritmo do tempo da pintura:

\footnotetext{
Da agulha chinesa imitando pintura gosto quando se entrelaçam fios de seda e cabelo animal (pelo) ou fios de seda e pelo vegetal (capim) - a exemplo desse sedoso leão sentado em repouso contemplativo quase sorrindo, tanta a suavidade que o cerca no capim doutorado e na fulva juba como se todas as fibras fossem só linhas de materiais diversos. (p.15)
}

Assim como o menino Benjamin, que se apaixonava pelo avesso do desenho bordado, Lu Menezes se sente atraída pelos bastidores do avesso. O último poema de Onde no mundo encerra-se com a imagem de um lírio branco, semelhante à página em branco, que "manifesta em sua alvura / a latência do futuro (p. 31)". Não sabemos qual flor Lu Menezes, quando criança, bordara, mas podemos fazer de conta que ela se aventurou a 
"bordar em linho branco / um lírio branco / com lastro / em whiteworks / e aroma / malevichiano (p. 30)". E “com ele / já bordado (Ibid.)", despediu-se do leitor, assim como eu me despeço, dizendo deste artigo: "É seu (Ibid.)".

ABSTRACT: This paper reflects on the gesture of embroidery in the selected works of artistc plastic José Leonilson and the poet Lu Menezes, through Walter Benjamin's thought about the childhood and especially the image of the "Sewing box" (Der Nähkasten), of Berlin childhood around 1900, that stores the tools that are given to children as an introductory activity to writing.

Keywords: writing; embroidery; poetry; visual arts; children's artistic language.

\footnotetext{
${ }^{1}$ Doutorando em Literatura, Cultura e Contemporaneidade pela PUC-Rio e pesquisador da Cátedra UNESCO de Leitura. E-mail: ftcamelo@ outlook.com

${ }^{2}$ MENEZES, Lu; MASSI, Augusto. Entrevista com Lu Menezes e Augusto Massi. [dez. 2016] Mato Grosso: Revista Alěre. Entrevista concedida a Masé Lemos. p. 1. Todas as referências à entrevista de Lu Menezes e Augusto Massi à Masé Lemos serão dadas em notas de rodapé, indicando somente o número das páginas.

${ }^{3}$ p. 4.

${ }^{4}$ Idem.

${ }^{5}$ p. 5.

${ }^{6}$ Todas as referências aos poemas de "Onde no mundo", que compõem o livro Gabinete de curiosidades, serão dadas no interior do texto, com o número das páginas entre parênteses.

${ }^{7}$ Ibid.

${ }^{8}$ p. 9.

9 p. 12

${ }^{10}$ Ibid.
}

\section{REFERÊNCIAS}

BENJAMIN, Walter. Rua de mão única. Tradução de Rubens Rodrigues Torres Filho e José Carlos Martins Barbosa. São Paulo: Brasiliense, 2012. (Obras escolhidas, v. 2).

-----. Magia e técnica, arte e política: ensaios sobre literatura e história da cultura. Tradução de Sérgio Paulo Rouanet. São Paulo: Brasilense, 2012b. (Obras escolhidas, v. 1)

BINES, Rosana Kohl. Contratempos de infância e morte. Revista Letras, Curitiba, ufpr, n. 95 2434, jan./jun. 2017.

CHIARA, Ana. Carta aos analistas: confissão da intimidade impossível. In: ------; ROCHA, Fátima Cristina Dias. Literatura brasileira em foco: escritas da intimidade. Rio de Janeiro: Casa Doze, 2009. p. 39-50.

DELEUZE, Gilles. A literatura e a vida. In: ------. Crítica e clínica. Tradução de Peter Pál Pelbart. São Paulo: Editora 34, 1997. p. 11-17.

GAGBENIN, Jeanne Marie. A criança no limiar do labirinto. In: História e narração em Walter Benjamin. São Paulo: Perspectiva, 2013. p. 73-92.

MENEZES, Lu; MASSI, Augusto. Gabinete de curiosidades. São Paulo: Luna Parque, 2016.

NIETZSCHE, Friedrich. Ecce homo: como alguém se torna o que é. Tradução de Paulo César Souza. $2^{a}$ ed. São Paulo: Editora Max Limonad, 1986. 
PEDROSA, Adriano. Leonilson: truth, fiction. São Paulo: Pinacoteca do Estado de São Paulo.

SARLO, Beatriz. Verdade dos detalhes. In: ------. Sete ensaios sobre Walter Benjamin e um lampejo. Tradução de Joana Angélica d'Avila Melo. Rio de Janeiro: Editora da UFRJ, 2013. p. 3949.

Data de envio: 02 de fevereiro de 2019

IPOTESI, JUIZ DE FORA, v.22, n.2, p.118-127, jul./dez. 2018 